\title{
Inequality in physical activity, global trends by income inequality and gender in adults
}

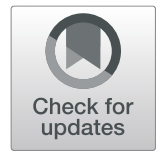

Chastin SFM ${ }^{1,2^{*}}$ D, J. Van Cauwenberg ${ }^{3}$, L. Maenhout ${ }^{2}$, G. Cardon², E. V. Lambert ${ }^{4}$ and D. Van Dyck ${ }^{2}$

\begin{abstract}
Background: Physical inactivity is a global pandemic associated with a high burden of disease and premature mortality. There is also a trend in growing economic inequalities which impacts population health. There is no global analysis of the relationship between income inequality and population levels of physical inactivity.

Methods: Two thousand sixteen World Health Organisation's country level data about compliance with the 2010 global physical activity guidelines were analysed against country level income interquantile ratio data obtained from the World Bank, OECD and World Income Inequality Database. The analysis was stratified by country income (Low, Middle and High) according to the World Bank classification and gender. Multiple regression was used to quantify the association between physical activity and income inequality. Models were adjusted for GDP and percentage of GDP spent on health care for each country and out of pocket health care spent.

Results: Significantly higher levels of inactivity and a wider gap between the percentage of women and men meeting global physical activity guidelines were found in countries with higher income inequality in high and middle income countries irrespective of a country wealth and spend on health care. For example, in higher income countries, for each point increase in the interquantile ratio data, levels of inactivity in women were $3.73 \%$ (Cl 0.89 6.57) higher, levels of inactivity in men were $2.04 \%$ (Cl 0.08 4.15) higher and the gap in inactivity levels between women and men was $1.50 \%$ larger $(\mathrm{Cl} 0.16$ 2.83). Similar relationships were found in middle income countries with lower effect sizes. These relationships were, however, not demonstrated in the low-income countries.
\end{abstract}

Conclusions: Economic inequalities, particularly in high- and middle- income countries might contribute to physical inactivity and might be an important factor to consider and address in order to combat the global inactivity pandemic and to achieve the World Health Organisation target for inactivity reduction.

Keywords: Economy, Inactivity, Guidelines, Physical activity, Gini index, Inequality, WHO activity guidelines

\section{Background}

Physical inactivity is a global pandemic [1] associated with negative physical and mental health outcomes like cardiovascular diseases, type 2 diabetes, obesity, some types of cancer, and depression; and a premature mortality burden estimated at 5.3 million death per annum [2].

\footnotetext{
* Correspondence: Sebastien.chastin@gcu.ac.uk

'School of Health and Life Sciences, Glasgow Caledonian University, Glasgow, UK

${ }^{2}$ Department of Movement and Sports Sciences, Ghent University, Ghent, Belgium

Full list of author information is available at the end of the article
}

Global surveillance data indicate that in 2016 levels of physical inactivity remained high (27.5\%) and stable over the previous 10 years, with a worrying eight percentage points gender inequality [3]. At the same time, there is a growing recognition that systemic changes, and not just individual behaviour change, are required to decrease levels of physical inactivity [4-8]. The World Health Organisation (WHO) has set a target for a $10 \%$ reduction in physical inactivity by 2025 , against which a global action plan was launched in 2018 [9]. As part of this plan, the global physical activity recommendations are updated this year for all age groups [10]. The WHO action plan for

(c) The Author(s). 2020 Open Access This article is licensed under a Creative Commons Attribution 4.0 International License, which permits use, sharing, adaptation, distribution and reproduction in any medium or format, as long as you give appropriate credit to the original author(s) and the source, provide a link to the Creative Commons licence, and indicate if changes were made. The images or other third party material in this article are included in the article's Creative Commons licence, unless indicated otherwise in a credit line to the material. If material is not included in the article's Creative Commons licence and your intended use is not permitted by statutory regulation or exceeds the permitted use, you will need to obtain permission directly from the copyright holder. To view a copy of this licence, visit http://creativecommons.org/licenses/by/4.0/ The Creative Commons Public Domain Dedication waiver (http://creativecommons.org/publicdomain/zero/1.0/) applies to the data made available in this article, unless otherwise stated in a credit line to the data. 
physical activity targets multiple factors and seeks synergies within society, societal systems and the environment in innovative ways. However, economic factors are noticeably absent from the WHO action plan and some of the proposed systems thought to determine population levels of physical activity [4]. The impact of the economic context on physical activity has received very little attention, this despite the rise in economic inequality globally and its impact on population health and health inequalities [11].

Therefore, the main aim of this paper is to examine the relationship between within-country income inequality and physical (in)activity and the gender gap in physical activity levels across countries worldwide. This, in order to understand if interventions targeting economic inequality should be investigated within public health campaigns against physical inactivity.

\section{Methods}

\section{Data sources}

Physical activity data were obtained from the World Health Organisation (WHO) estimate pooled from 358 surveys in 168 countries [3]. In this data, insufficient physical activity was defined as adults not meeting the 2010 WHO physical activity guidelines for health [12] -i.e., at least $150 \mathrm{~min}$ of moderate-intensity, or $75 \mathrm{~min}$ of vigorous-intensity physical activity per week, or any equivalent combination of the two. For this study we used the published age-standardised estimated prevalence [3] in the country as a whole, and for men and women separately, who were not meeting the guidelines for the most recent year available in each country (ranging from 2001 to 2016). The age-standardisation was performed by Guthold et al. to account for the possible influence of difference in age distribution between countries. In addition, we computed the activity gender gap by calculating the difference in estimated compliance to the guidelines between men and women. A higher activity gender gap indicates that within a country more men are meeting the WHO physical activity guidelines than women.

Income inequality, i.e. the difference between those with the highest and lowest incomes in a society, is linked with population health, independent of the income of individuals [11, 13, 14]. Economic inequality was measured as income interquantile ratio (S80/20), which compares the income of the top 20\% richest to the poorest $20 \%$ within a country [15]. This measure of economic inequality is used by international agencies such as the United Nation, World Bank and OECD. S80/20 data were obtained from the World Bank Development Research Group database [16], the World Income Inequality Database [17] and the OECD Income Distribution Database [18]. For more information about the World Bank methodology see [19]. To ensure that we used only robust data, we cross-referenced data from the WIID OECD and World Bank and excluded data when the estimates were more than 20\% apart [20].

Gross Domestic Product (GDP) data were from the World Bank Development research group [16]. Current health care expenditure and out of pocket health care expenditure were also obtained from the World Bank Development research group [16] and cross referenced against the World Health Organisation Global Health Expenditure Database [21].

We used inequality, GDP and health care spent data concurrent to the year of the physical activity estimates for each country or from the closest previous year when not available.

\section{Analysis}

We used multiple regression to investigate the relationship between income inequality and insufficient physical activity levels at country level. We stratified the analysis by World Banks income group [22]. In the models, the dependent variables were the percentage of the whole, male and female population who are inactive and the activity gender gap. We first estimated their association with S80/20 adjusting for each country GDP so that the association reflected the relationship with inequality adjusted for country's wealth. We then further adjusted the models for country level and out of pocket health care expenditure. We conducted sensitivity analysis by removing $10 \%$ of the data in each income group and repeating the analysis. All models were checked for compliance with assumptions necessary for multiple linear regression.

\section{Results}

In total, full data were available for 84 countries (24 from low income, 34 from middle income and 26 from high income countries). Summary statistics are given per income group in Table 1. The relationship between insufficient physical activity and income inequality is depicted graphically in Fig. 1, with raw regression line in black for whole population, blue for male population and red for female population level of insufficient physical activity. An additional plot showing the country names is available in the supplementary materials.

Figure 1 shows that there is a trend toward higher insufficient physical activity levels in countries with higher income inequalities in middle and high income countries. The gradient of this relationship appears steeper for women than men. This becomes more apparent in Fig. 2 which shows that in high and middle income countries, the gender activity gap is higher in those countries with higher income inequalities. The linear regression confirmed that the relationships in Figs. 1 and 2 were statistically significant at $p<0.05$ level for both 
Table 1 Summary statistics for insufficient physical activity levels, activity gender gap and income inequality by country income group, given as median and interquartile range

\begin{tabular}{|c|c|c|c|}
\hline Country Income group & Low & Middle & High \\
\hline Whole population insufficient physical activity (\%) & $15.5(14.322 .6)$ & $27.5(18.736 .3)$ & $31.1(28.437 .3)$ \\
\hline Male population insufficient physical activity (\%) & $12.7(10.819 .6)$ & $21.2(17.37$ 28.8) & $27.4(25.431 .7)$ \\
\hline Female population insufficient physical activity (\%) & $18.7(16.9$ 26.1) & $31.8(23.640 .4)$ & $33.95(31.340 .8$ \\
\hline Activity gender gap (\%) & $6.30(3.308 .30)$ & $9.45(6.3315 .5)$ & $7.25(4.389 .50)$ \\
\hline S80/20 & $7.37(6.508 .95)$ & $7.44(5.609 .31)$ & $5.06(4.295 .74)$ \\
\hline Health care expenditure (\% of GDP) & $6.00(5.008 .00)$ & $6.00(4.257 .75)$ & $9.00(8.0010 .0)$ \\
\hline Out of pocket (\% health expenditure) & $42.0(31.561 .0)$ & $32.5(23.640 .4)$ & $16.0(14.022 .5)$ \\
\hline
\end{tabular}

high and middle income countries (Table 2) and independent of country wealth, as measured by GDP. Adjusting for health care expenditure and out of pocket health care expenditure did not change these relationships. Models explained around $20 \%$ of the variance in insufficient physical activity for high and middle income countries. The model predicts that if there was no income inequality the residual insufficient physical activity would be 12 to $15 \%$ in high and middle income countries and the gender activity gap would disappear.

Repeated analysis with $10 \%$ of the data removed by country income level performed as a sensitivity analysis did not change the models significantly (Supplementary material Table S2). The sensitivity analysis showed that the relationships were robust.

\section{Discussion}

Our results show that the levels of insufficient physical activity in high and middle-income countries are higher where there are greater income inequalities, regardless of the country wealth or health care expenditure. In addition, the gender inequality in terms of physical activity levels is also greater in high- and middle- income countries with higher income inequalities. Conversely, these trends are flatter and even inverse in low-income countries. The models estimate that for a point increase

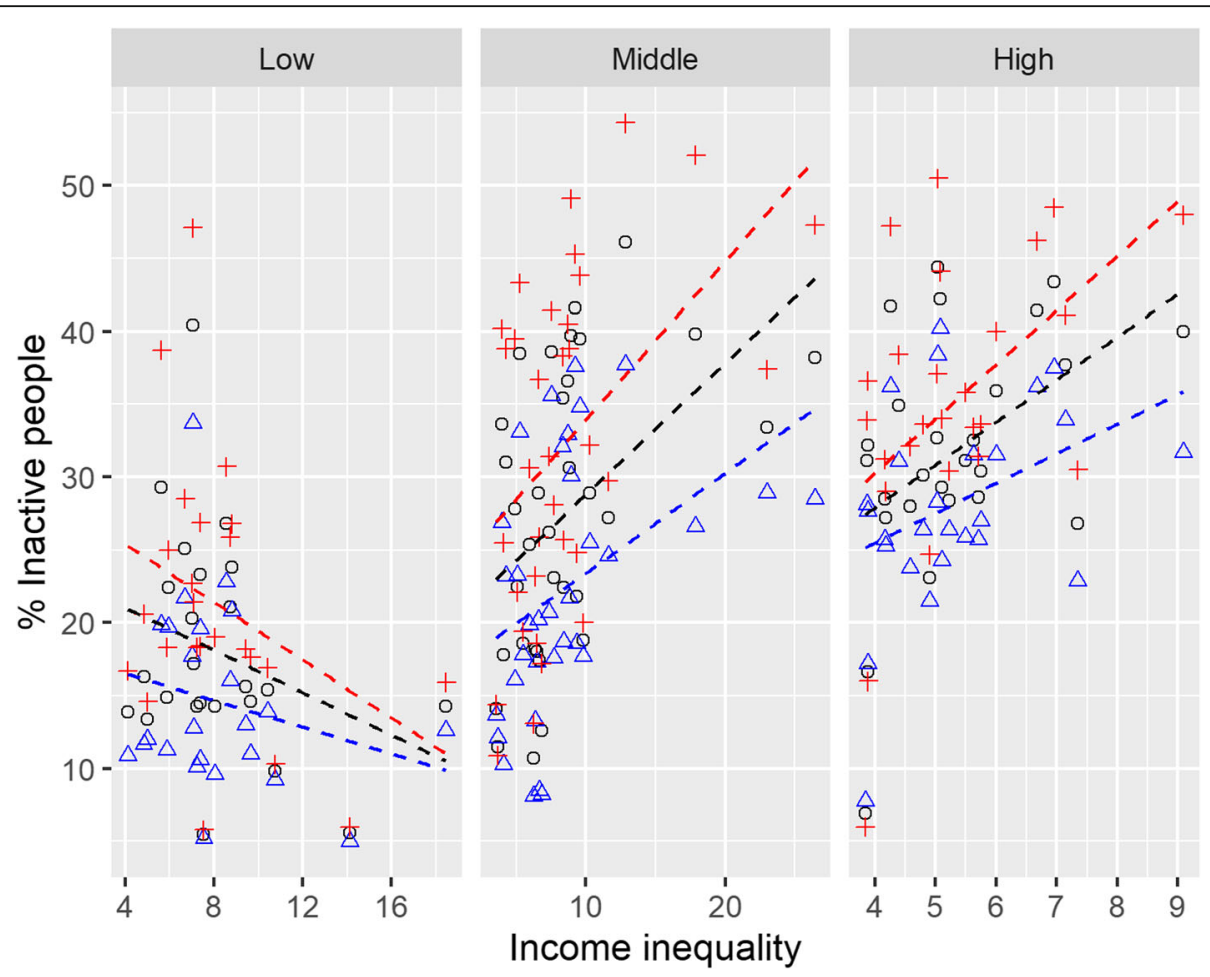

Fig. 1 Relationship between insufficient physical activity and income inequality by World bank income group. Whole country population data are in black (o), male data are in blue $(\Delta)$ and female in red (+). Raw association are plotted as dashed line with the same colour coding 

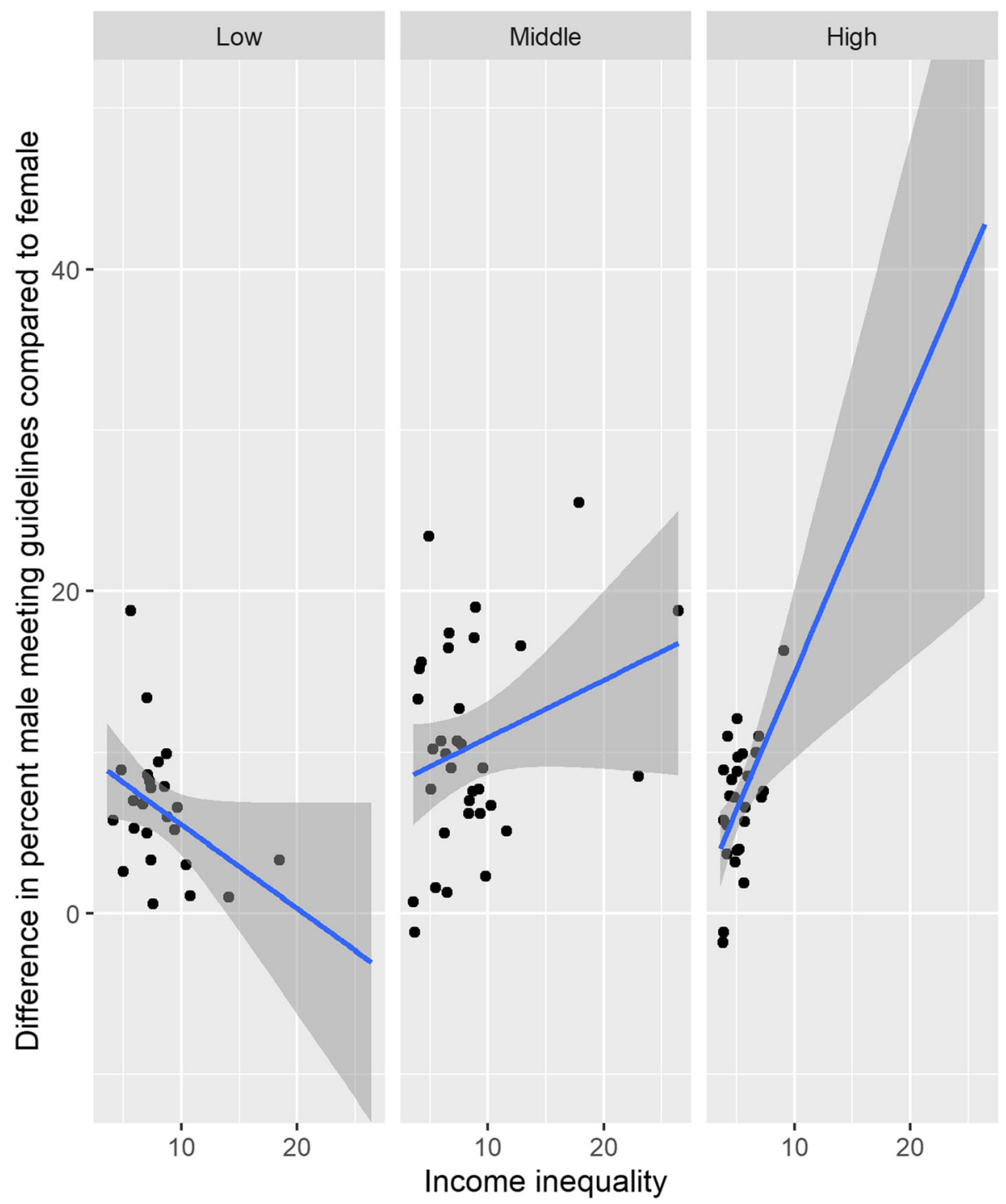

Fig. 2 Relationship between gender activity gap and Income inequality per World Bank country income group. Blue lines show the trend with 95\% confidence intervals shown as grey ribbons. The income inequality scale are kept identical between plots to facilitate comparision

Table 2 Multiple regression unadjusted coefficients with 95\% confidence intervals. Significant associations at $p<0.05$ are highlighted in bold

\begin{tabular}{llll}
\hline Country Income Group & High & Mid & Low \\
\hline Raw association & & & \\
Whole population & $\mathbf{2 . 9 3}(\mathbf{0 . 4 8} \mathbf{5 . 3 7})$ & $\mathbf{0 . 9 0}(\mathbf{0 . 2 8} \mathbf{1 . 5 2})$ & $-0.73(-1.780 .32)$ \\
Male & $\mathbf{2 . 0 4}(\mathbf{0 . 0 8} \mathbf{4 . 1 5})$ & $\mathbf{0 . 6 9}(\mathbf{0 . 1 2} \mathbf{1 . 2 6})$ & $-0.45(-1.350 .44)$ \\
Female & $\mathbf{3 . 7 3}(\mathbf{0 . 8 9} \mathbf{6 . 5 7})$ & $\mathbf{1 . 1 0}(\mathbf{0 . 3 5} \mathbf{1 . 8 3})$ & $-0.99(-2.240 .26)$ \\
Activity gender gap & $\mathbf{1 . 7 0}(\mathbf{0 . 6 0} \mathbf{2 . 8 0})$ & $\mathbf{0 . 3 6}(\mathbf{0 . 0 9} \mathbf{0 . 8 0})$ & $-0.55(-1.060 .02)$ \\
Models adjusted for health care expenditure & & & $-0.56(-1.690 .57)$ \\
Whole population & $\mathbf{3 . 0 0}(\mathbf{0 . 1 7} \mathbf{5 . 8 3})$ & $\mathbf{0 . 8 5}(\mathbf{0 . 1 8} \mathbf{1 . 5 1})$ & $-0.34(-1.310 .63)$ \\
Male & $\mathbf{2 . 2 0}(\mathbf{0 . 2 1} \mathbf{4 . 6 2})$ & $\mathbf{0 . 5 5}(\mathbf{0 . 0 3} \mathbf{1 . 1 3})$ & $-0.77(-2.110 .57)$ \\
Female & $\mathbf{3 . 7 0}(\mathbf{0 . 3 9} \mathbf{7 . 0 2})$ & $\mathbf{1 . 1 1}(\mathbf{0 . 3 1} \mathbf{1 . 9 2})$ & $-0.43(-0.161 .02)$ \\
Activity gender gap & $\mathbf{1 . 5 0}(\mathbf{0 . 1 6} \mathbf{2 . 8 3})$ & $\mathbf{0 . 5 4}(\mathbf{0 . 1 0} \mathbf{0 . 9 7})$ & \\
\hline
\end{tabular}


in income inequality there is a $3 \%$ increase in insufficient physical inactivity for the whole population, $2.2 \%$ for men and $3.7 \%$ for women in high income countries. A point different in income inequality is roughly the difference between income inequality in France and the United Kingdom. Considering that the difference in insufficient physical activity levels between these countries is around 6\%, income inequality could account for half this difference. Similarly compared to the $5 \%$ increase in insufficient physical activity observed in high income countries by Guthold et al. [3] over 15 years the estimated effect size of income inequality appears large. The association is about a third weaker in middle income countries.

Our findings extrapolate on a global scale what has already been observed within the USA. Two studies previously examined the association between income inequality and physical (in)activity between states in the USA [23, 24]. Diez-Roux and colleagues found that state-level inequality was associated with higher levels of physical inactivity (i.e. not meeting the physical activity guidelines) in US adults [23]. Similarly, another USA study found that state-level income inequality was associated with a lower likelihood of meeting the physical activity recommendations, but only among women [24].

Many studies have demonstrated that people living in areas with high income inequality are at higher risk for premature mortality and other negative health outcomes, like cardiovascular diseases, depression, obesity and lower self-rated health as demonstrated [25-27]. Considering the physical inactivity is associated with poor health, it is possible that inequality in physical activity plays an important role the relationship between income inequality and poor health.

Several hypotheses exist to explain why income inequality contributes to poorer health outcomes. On the one hand, the social capital hypothesis posits that income inequality intensifies social hierarchies and social inequality and consequently reduces population health through decreased interpersonal trust, social cohesion and social capital $[13,28]$. On the other hand, the neomaterialist hypothesis claims that income inequality leads to underinvestment in health services and infrastructures, and education, and thus to poorer health $[29,30]$.

Income inequality might be an important determinant of insufficient physical activity and poor health that needs to be more clearly understood and taken into account. Negative associations between income inequality and health outcomes are usually found in large areas like countries or states, while findings are less consistent at the level of cities, counties or neighbourhoods [31-34]. This suggests that income inequality could be acting on large systemic scale and at societal level, hinting that high level policy measures are required to address it. For example, the Hass Institute proposed six evidence based policy solutions to reverse inequality: increase minimum wage, expand the earned income tax, build assets for working families, invest in education, make tax more progressive, end residential segregation [35]. Reducing income inequality might be an important lever to increase global physical activity and physical activity equity and prevent raise in inactivity and activity gender gap as countries transition from low income to middle- and high-income economies. Alternatively, it is possible that finer grained analyses are better equipped to account for confounders. However, small geographical scale analysis might not allow to capture macroscopic systemic effects.

Another possible explanation for differences in association between income inequality in high and middle income settings versus low-income countries, may be related to differences in the nature of physical activity and whether it is volitional or utilitarian physical activity. Stalsberg and Pedersen recently showed that the only consistent relationship between self-reported physical activity and socioeconomic status (SES) was for recreational or leisure-time physical activity, and that while persons with low SES did not have resources to direct to leisure time physical activity, they were more actively engaged in physical activity in other domains [36]. This supports the findings by Guthold et al. (2011) of 22 countries in the African region, most of which were low income countries, in which over $79 \%$ were meeting WHO global physical activity recommendations [37]. However, the vast majority of physical activity was utilitarian, in the form of occupational $(48.6 \%)$ or transportrelated (46.3\%) physical activity, with only 5.3\% accounted for by leisure time activities. The gender gap was also greatest for leisure time activity, and any form of vigorous activity. Similarly, Atkinson et al. found marked differences in inactivity levels in low income countries according to occupational structure [38].

In considering why income inequality has a differential effect on levels of physical activity in high- and middleincome countries, compared to low income countries, we can think of the broader upstream factors, such as infrastructure and access to facilities and resources, or social determinants such as safety from crime. In a recent narrative review, Adkins et al. suggested that in low-income, socio-economically disadvantaged communities, the associations between the built environment and physical activity are weaker and often inverse [39]. This is supported by a number of studies. For example, Da Silva (2014) demonstrated in a study of over 100,000 Brazilian adolescents, from more than 2800 schools that physical activity in adolescents was inversely associated with income inequality of the city in which they lived [40]. Da Silva suggests that one way in which to address this social gradient, or "level the playing fields" in cities 
would be to develop the infrastructure to promote physical activity for the entire population, through constructing "free-access public areas" such as parks, sports fields, recreation facilities, and greenways.

In terms of other attributes of the built environment, residential density in high -income countries and the Global North has been associated with increased walking for leisure [41]. Conversely, densification in low-income country settings reflects overcrowding and has little or no association, and may, in fact, be negatively associated with walking for leisure [42]. The results of the current study suggest that it is important to consider both the volitional and utilitarian nature of physical activity, infrastructure, programmes, densification and the quality of what comprises the urban space, against the needs of the inhabitants and their perceptions [43].

To date the promotion of physical activity has mainly focused on individual behaviour change, communitybased interventions and sport promotion [8] with only limited impact on global trends in inactivity [3]. Some might argue that the focus on sport might be counterproductive as it possibly re-inforces social hierarchy and hence the potential effect of inequality on inactivity above [44]. It is also possible to raise the question of whether physical inactivity might be a symptom of inequality (a consequence), rather than mainly a behavioural issue exacerbated in high income countries. Proximal determinants targeted by most behavioural interventions only explain a small proportion of the variance in population physical activity [45, 46]. Conversely, it appears that income inequality could explain around $20 \%$ of the variance suggesting that it could be a much more powerful lever. Recent report show that we are not on course to meet the WHO target for a $10 \%$ reduction in physical inactivity [3]. Our model estimates that $10 \%$ lower physical inactivity is associated with an income inequality lowered by a factor of 3 in high income countries. For example, this would be equivalent to bring levels of inequality in the USA to the levels observed in Norway which Norway as a country show it is feasible. Considering the $\$ 53.8$ billion economic burden and $\$ 13.7$ billion productivity loss associated with physical inactivity, which are probably underestimated, reducing income inequality might make economic as well as public health sense [47].

\section{Strength and limitations}

The main strength of this study is that we used data openly available from international agencies such as the WHO, UN and World Bank and cross-referenced them. The main limitations are with the quality of the data. Measures of income inequality are also notoriously imprecise [15]. In addition, it is recognised that wealth inequality might be a stronger driver of outcome inequality than income inequality. Nonetheless, the relationships observed are quite apparent without the need of complex analysis which give some support to their robustness. Finally, this is only a cross-sectional analysis therefore it is not possible to offer definitive answer about whether these are causal relationships or simply concurrent phenomena.

\section{Conclusion}

Physical inactivity levels and gender gap in activity levels are strongly related to within country income inequality in high and middle income countries. Economic inequalities might contribute to the global pandemic of physical inactivity and might be an important factor to consider and address in order to achieve the World Health Organisation target for inactivity reduction and combat the pandemic and its associated burden of disease and mortality.

\section{Supplementary Information}

The online version contains supplementary material available at https://doi. org/10.1186/s12966-020-01039-x.

\begin{abstract}
Additional file 1: Fig. S1: Relationship in low income countries between within country income inequality and percentage of people inactive within a country. Country code are presented and can be crossreferenced with real names in Table S1. The linear raw association is presented with 95\% Cl ribbon. Fig. S2: Relationship in middle income countries between within country income inequality and percentage of people inactive within a country. Country code are presented and can be cross-referenced with real names in Table S1. The linear raw association is presented with $95 \%$ Cl ribbon. Fig. 3: Relationship in high income countries between within country income inequality and percentage of people inactive within a country. Country code are presented and can be cross-referenced with real names in Table S1. The linear raw association is presented with 95\% Cl ribbon. Table S1: Country code and name reference table. Table S2: Results of sensitivity analysis.
\end{abstract}

\section{Acknowledgements}

The authors would like to thank Richard Wilkinson, Melody Ding and Fiona Bull for constructive discussions.

\section{Authors' contributions}

SC and JVC conceived the study; SC, LM and JVC dealt with data processing and analysis; SC, DVD wrote the first draft and all authors contributed text, comments, analysis and interpretations to the final manuscript. All author(s) read and approved the final manuscript.

Funding

The work in this manuscript is not supported by any funding.

Availability of data and materials

All data used in this manuscript are freely available, the references are given in the main text.

Ethics approval and consent to participate

This is a secondary analysis study dealing with country level aggregated data. Ethics was thought by the studies which provided these aggregates [3]

Consent for publication

Not applicable.

Competing interests

The authors declare that they have no competing interests. 


\section{Author details}

'School of Health and Life Sciences, Glasgow Caledonian University, Glasgow, UK. ${ }^{2}$ Department of Movement and Sports Sciences, Ghent University, Ghent, Belgium. ${ }^{3}$ Department of Public Health and Primary Care, Ghent University, Ghent, Belgium. ${ }^{4}$ Health through Physical Activity, Lifestyle and Sport Research Centre (HPALS), Department of Human Biology, Faculty of Health Sciences, University of Cape Town, Cape Town, South Africa.

Received: 18 May 2020 Accepted: 20 October 2020

Published online: 26 November 2020

\section{References}

1. Kohl HW 3rd, Craig CL, Lambert EV, Inoue S, Alkandari JR, Leetongin G, et al. The pandemic of physical inactivity: global action for public health. Lancet. 2012;380:294-305 Available from: http://view.ncbi.nlm.nih.gov/pubmed/22 818941. harold.w.koh!@uth.tmc.edu. University of Texas Health Science Center, Houston School of Public Health, USA.

2. Lee I-M, Shiroma EJ, Lobelo F, Puska P, Blair SN, Katzmarzyk PT. Effect of physical inactivity on major non-communicable diseases worldwide: an analysis of burden of disease and life expectancy. Lancet. 2012;380:219-29 Available from: http://linkinghub.elsevier.com/retrieve/pii/S014067361261031 9. Elsevier. [cited 2016 Jun 16].

3. Guthold R, Stevens GA, Riley LM, Bull FC. Worldwide trends in insufficient physical activity from 2001 to 2016: a pooled analysis of 358 populationbased surveys with 1.9 million participants. Lancet Glob Heal. 2018.

4. Rutter H, Cavill N, Bauman A, Bull F. Systems approaches to global and national physical activity plans. Bull. World Health Organ: World Health Organization; 2019. p. 162-5.

5. Chastin SFM, De Craemer M, Lien N, Bernaards C, Buck C, Oppert J-M, et al. The SOS-framework (Systems of Sedentary behaviours): an international transdisciplinary consensus framework for the study of determinants, research priorities and policy on sedentary behaviour across the life course: a DEDIPAC-study. Int J Behav Nutr Phys Act. 2016;13:83.

6. Condello G, Ling FCM, Bianco A, Chastin S, Cardon G, Ciarapica D, et al. Using concept mapping in the development of the EU-PAD framework (EUropean-Physical Activity Determinants across the life course): a DEDIPACstudy. BMC Public Health. 2016;16:1-16. https://doi.org/10.1186/s12889-0163800-8 BioMed Central Ltd. [cited 2020 Mar 24].

7. Holdsworth M, Nicolaou M, Langøien LJ, Osei-Kwasi HA, Chastin SFM, Stok FM, et al. Developing a systems-based framework of the factors influencing dietary and physical activity behaviours in ethnic minority populations living in Europe - a DEDIPAC study. Int J Behav Nutr Phys Act. 2017;14:154.

8. Hallal PC, Bauman AE, Heath GW, Kohl HW, Lee IM, Pratt M. Physical activity: More of the same is not enough. Lancet. 2012:190-1 Lancet Publishing Group.

9. World Health Organisation. Global action plan on physical activity 20182030: more active people for a healthier world. 2018.

10. World Health Organization. Guidelines on physical activity and sedentary behaviour. Geneva; 2020.

11. Bor J, Cohen GH, Galea S. Population health in an era of rising income inequality: USA, 1980-2015. Lancet. 2017;389:1475-90.

12. World Health Organisation. Global Recommendations on Physical Activity for Health. Geneva: 2010.

13. Pickett K, Wilkinson R. The Spirit Level: Why Greater Equality Makes Societies Stronger. Blomsbury. New York; 2009.

14. Subramanian SV, Kawachi I. Income inequality and health: what have we learned so far? Epidemiol Rev. 2004;26(1):78-91.

15. De Maio FG. Income inequality measures. J Epidemiol Community Health. 2007:849-52.

16. World Bank. World Bank Development Research Group indicators database [Internet]. Available from: https://data.worldbank.org/indicator.

17. United Nations University. World Income Inequality Database. 2018. Available from: https://www.wider.unu.edu/data.

18. OECD. Income inequality (indicator). doi: https://doi.org/10.1787/459aa7f1en (Accessed on 25 March 2020). 2020; Available from: https://data.oecd. org/inequality/income-inequality.htm.

19. World Bank. PovcalNet: an online analysis tool for global poverty monitoring [Internet]. Available from: http://iresearch.worldbank.org/ PovcalNet/home.aspx.

20. Gasparini L, Tornarolli L. A review of the OECD Income Distribution Database. J Econ Inequal. 2015;13:579-602.
21. World Health Organization. Global Health Expenditure Database. 2020. Available from: https://apps.who.int/nha/database/Select/Indicators/en.

22. World Bank. List of economies, December 2016. databank. [Internet]. 2016 [cited 2020 Mar 23]. Available from: www.worldbank.org/data/download/ site-content/CLASS.xls.

23. Diez-Roux AV, Link BG, Northridge ME. A multilevel analysis of income inequality and cardiovascular disease risk factors. Soc Sci Med. 2000;50(5): 673-87.

24. Pabayo R, Fuller D, Lee EY, Horino M, Kawachi I. State-level income inequality and meeting physical activity guidelines; Differential associations among US men and women. J Public Heal (United Kingdom). 2018;40(2): 229-36.

25. Kondo N, Sembajwe G, Kawachi I, Van Dam RM, Subramanian SV, Yamagata Z. Income inequality, mortality, and self rated health: meta-analysis of multilevel studies. BMJ. 2009:339:b4471.

26. Pabayo R, Kawachi I, Gilman SE. Income inequality among American states and the incidence of major depression. J Epidemiol Community Health. 2014;68(2): 110-5.

27. Kim D, Kawachi I, Hoorn S, Vander Ezzati M. Is inequality at the heart of it? Cross-country associations of income inequality with cardiovascular diseases and risk factzors. Soc Sci Med. 2008;66(8):1719-32.

28. Kawachi I, Kennedy B. Health and social cohesion: why care about income inequality? BMJ. 1997:314:1037-40.

29. Dunn JR, Burgess B, Ross NA. Income distribution, public services expenditures, and all cause mortality in US states. J Epidemiol Community Health. 2005;59(9):768-74.

30. Ronzio CR, Pamuk E, Squires GD. The politics of preventable deaths: local spending, income inequality, and premature mortality in US cities. J Epidemiol Community Health. 2004;58:175-9.

31. Clough-Gorr KM, Egger M, Spoerri A. A Swiss paradox? Higher income inequality of municipalities is associated with lower mortality in Switzerland. Eur J Epidemiol. 2015;30(8):627-36.

32. Cohen SA, Greaney ML, Klassen AC. A "swiss paradox" in the United States? Level of spatial aggregation changes the association between income inequality and morbidity for older Americans. Int J Health Geogr. 2019;18:28.

33. Wilkinson RG, Pickett KE. Income inequality and population health: a review and explanation of the evidence. Soc Sci Med. 2006;62(7):1768-84.

34. Pickett KE, Wilkinson RG. Income inequality and health: a causal review. Soc Sci Med. 2015;128:316-26.

35. Hass institute for a fair and inclusive society. Responding to Rising Inequality: Policy Interventions to Ensure Opportunity for All. 2014.

36. Stalsberg R, Pedersen AV. Are differences in physical activity across socioeconomic groups associated with choice of physical activity variables to report? Int J Environ Res. Public Health. 2018;15(5):922.

37. Guthold R, Louazani SA, Riley LM, Cowan MJ, Bovet P, Damasceno A, et al. Physical activity in 22 African countries. Am J Prev Med. 2011;41(1):52-60.

38. Atkinson K, Lowe S, Moore S. Human development, occupational structure and physical inactivity among 47 low and middle income countries. Prev Med Reports. 2016;3:40-5.

39. Adkins A, Makarewicz C, Scanze M, Ingram M, Luhr G. Contextualizing walkability: do relationships between built environments and walking vary by socioeconomic context? J am plan Assoc. 2017;83(3):296-314.

40. Silva DAS. Relationship between brazilian adolescents' physical activity and social and economic indicators of the cities where they live. Percept Mot Skills. 2015.

41. Christiansen LB, Troelsen J, Cerin E, Badland H, Kerr J, Davey R, et al. International comparisons of the associations between objective measures of the built environment and transport-related walking and cycling: IPEN adult study. J Transp Heal. 2016;3:467-78.

42. Lu Y, Xiao Y, Ye Y. Urban density, diversity and design: is more always better for walking? A study from Hong Kong. Prev Med (Baltim). 2017.

43. Boyko C. Urban Design and Well-being. In: R. TE and C, editor. Des Heal. Routledge; 2017.

44. Bourdieu P. Sport and social class. Soc Sci Inf. 1978;17:819-40. Sage PublicationsSage CA: Thousand Oaks, CA; [cited 2020 May 5]. https://doi. org/10.1177/053901847801700603.

45. Condello G, Puggina A, Aleksovska K, Buck C, Burns C, Cardon G, et al. Behavioral determinants of physical activity across the life course: a "DEterminants of Dlet and physical ACtivity" (DEDIPAC) umbrella systematic literature review. Int J Behav Nutr Phys Act. 2017. 
46. Brug J, van der Ploeg HP, Loyen A, Ahrens W, Allais O, Andersen LF, et al. Determinants of diet and physical activity (DEDIPAC): a summary of findings. Int J Behav Nutr Phys Act. 2017;14:150.

47. Ding D, Lawson KD, Kolbe-Alexander TL, Finkelstein EA, Katzmarzyk PT, van Mechelen W, et al. The economic burden of physical inactivity: a global analysis of major non-communicable diseasees. Lancet. 2016;388:1311-24.

\section{Publisher's Note}

Springer Nature remains neutral with regard to jurisdictional claims in published maps and institutional affiliations.

Ready to submit your research? Choose BMC and benefit from:

- fast, convenient online submission

- thorough peer review by experienced researchers in your field

- rapid publication on acceptance

- support for research data, including large and complex data types

- gold Open Access which fosters wider collaboration and increased citations

- maximum visibility for your research: over $100 \mathrm{M}$ website views per year

At $B M C$, research is always in progress.

Learn more biomedcentral.com/submissions 